\title{
Augmentation/Transplantation in Periodontally Compromised Dentition
}

\author{
Simone Esser ${ }^{1-4, *}$ \\ ${ }^{1}$ Master of Oral Medicine, Schleiden, Germany \\ ${ }^{2}$ Master of Science in Implantology and Dental Surgery MSc, Schleiden, Germany \\ ${ }^{3}$ Master of Science in Periodontology MSc, Schleiden, Germany \\ ${ }^{4}$ Oral Surgery Specialist, Schleiden, Germany
}

*Corresponding author: Simone Esser, Master of Oral Medicine, Schleiden, Germany, E-mail: Esser@dr-simone-esser.de, esser@dr-simone-esser.de

Received: 21 Sep, 2019 | Accepted: 01 Oct, 2019 | Published: 18 Oct, 2019

Citation: Esser S (2019) Augmentation/Transplantation in Periodontally Compromised Dentition. Int J Dent Oral Health 5(6): dx.doi. org/10.16966/2378-7090.305

Copyright: (C) 2019 Esser S. This is an open-access article distributed under the terms of the Creative Commons Attribution License, which permits unrestricted use, distribution, and reproduction in any medium, provided the original author and source are credited.

Keywords: Aggressive periodontitis; Bone resorption; Vertical bone defects; Alveolar ridge augmentation; Periodontal and implant rehabilitation; Allogeneic bone-block graft

\section{The Patient Case}

A non-smoking 51-year-old patient who had received various periodontal treatments at a different institution presented to us with pronounced and aggressive periodontitis [1] and unilateral free-end edentulism in the region of the left posterior maxilla. The following technical article describes how, by use of extensive periodontal measures, the periodontal and implant rehabilitation of the patient's compromised oral condition was eventually achieved by means of an allogeneic bone-block graft (Figure 1).

The patient had been receiving periodontal treatment for five years, and two of his teeth, 26 and 27, eventually had to be removed. The clinical observation that the patient was suffering from loose teeth and gingival recession eventually brought him to our practice clinic.

\section{Findings and Treatment}

In 2015, after a comprehensive assessment and screening process, microbiological identification (Figure 2, Hauss Laboratory, Kiel) and radiological assessment (Figure 3), the patient was initially prescribed $125 \mathrm{mg}$ of amoxicillin 500/clavulanic acid (1-1-1 over 10 days) as an adjuvant to closed full-mouth curettage.

When the patient was re-evaluated, increased probing depths of up $12 \mathrm{~mm}$ were observed around teeth 14, 15, 24 and 25. The radiological examination revealed discernible vertical bone defects in conjunction with Bleeding on Probing (BOP), resulting in a plan to conduct regenerative periodontal surgical treatment, initially around teeth 14 and 15 (Figures 4 and 5).

A further re-evaluation 10 weeks after surgery revealed that the probing depths around teeth 14 and 15 had reduced $2,5 \mathrm{~mm}$ and that the patient's overall clinical picture had improved, which was due to the patient's high motivation and good cooperation (Figure 6).

\section{Pre-operative Planning}

The following plan for 2017 was to perform open curettage of the deep vertical bone defect in tooth regions 24 and 25 in conjunction with an allogeneic bone-block graft (Zimmer Dental $\mathrm{GmbH}$, Munich). With regard to tooth 25 , it was explained to the patient that a decision could and would have to be made intra-operatively whether to retain the tooth by means of regenerative measures, based on the experiences of Cortellini P, et al. [2], or to remove it.

The alveolar ridge of tooth regions 26 and 27, which was affected by severe three-dimensional atrophy, was to be reconstructed with an allogeneic bone block. A CT scan was taken to help plan the surgery. This was used as the basis for the fabrication of a 3D bone block. The CT data were sent in DICOM format to Zimmer Dental GmbH, Munich for virtual graft planning (Figures 7 and 8).

The analysis strikingly revealed, more so than the planning, the periodontal defect of vertical bone loss in tooth regions 24 and 25. Figures 9 and 10 shows the virtual planning after grafting the bone block onto the defective area.

The material used to fabricate the individual bone blocks is processed human cancellous bone (from living donors only) (Puros Allograft, Zimmer Dental GmbH, Munich) [3].

\section{Surgical Protocol}

In January 2017, the defective regions around teeth 24-27 were imaged under intubation anaesthesia.

The representation of the surgical site by the previously prepared full flap revealed a pronounced vertical bone defect around teeth 24 and 25; tooth 24 was only attached to the bone by its apex. Based on the available evidence about regenerative measures and because 


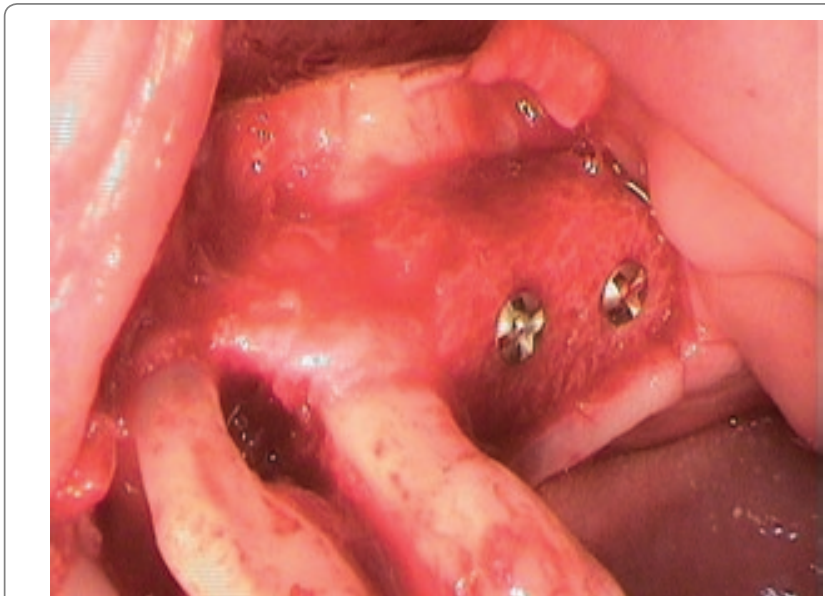

Figure 1: Intraoperative site after allogeneic bone-block graft and during open curettage of teeth 24 and 25 .

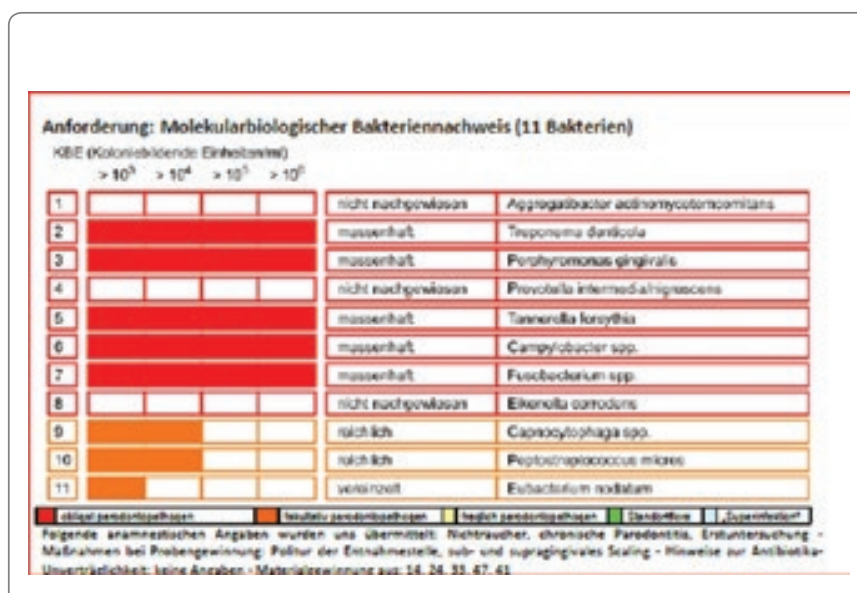

Figure 2: Microbiological analysis (Dr Hauss Laboratory, Kiel).

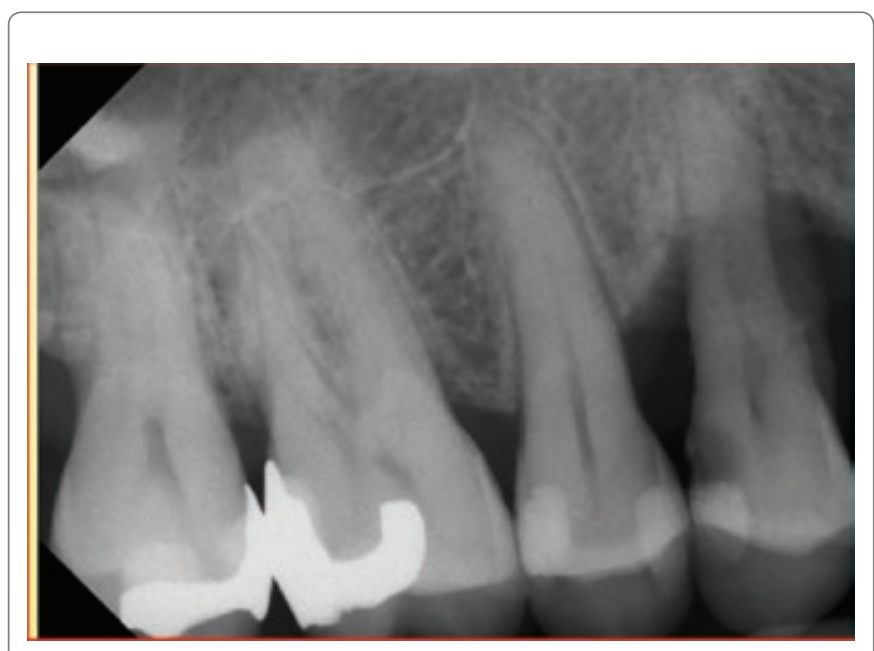

Figure 3: Tooth regions 14 and 15 before closed curettage; a composite filling was used to treat the carious lesion.

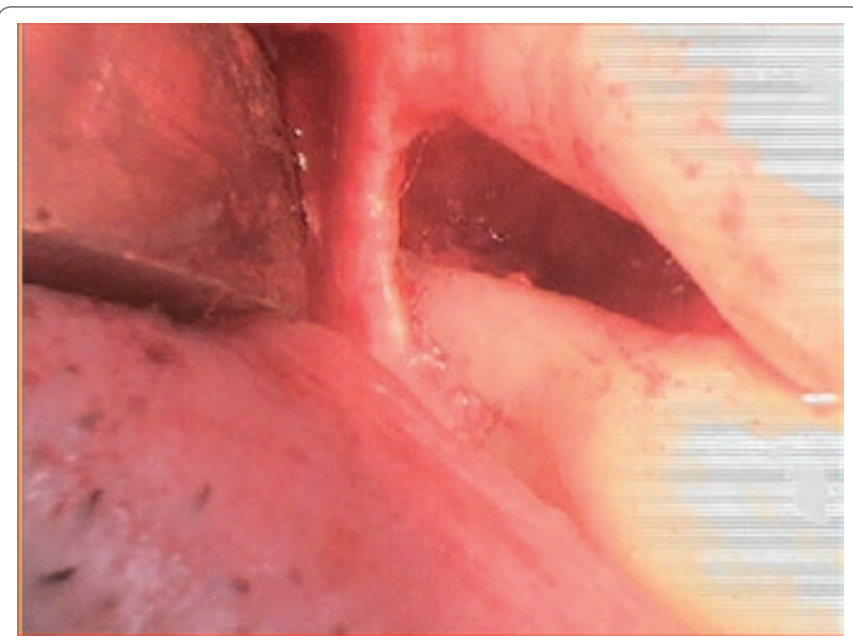

Figure 4: Surgical site during regenerative periodontal surgery of tooth 14 .

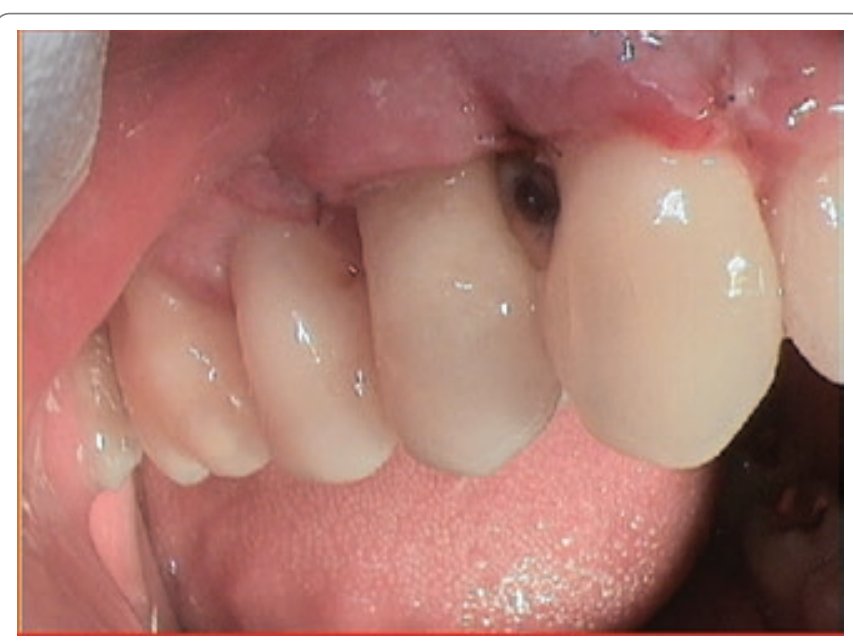

Figure 5: Clinical situation one week after regenerative treatment with Emdogain ${ }^{\circledR}$ (Straumann) and Bio-Oss ${ }^{\circledR}$ collagen (Geistlich) teeth 14 and 15.

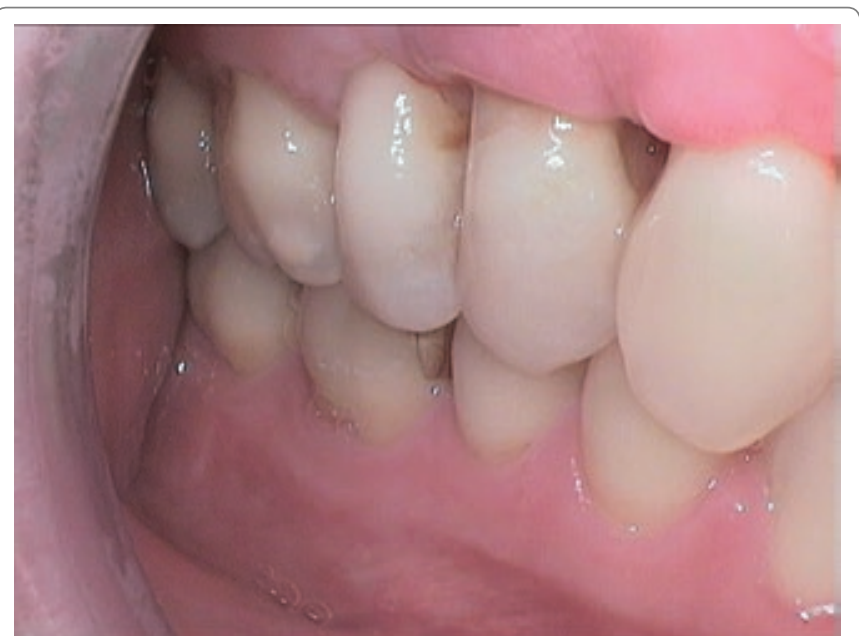

Figure 6: Clinical situation 10 weeks after regenerative therapy during around teeth 14 and 15 after closed curettage and open curettage with adjuvant antibiotics. 


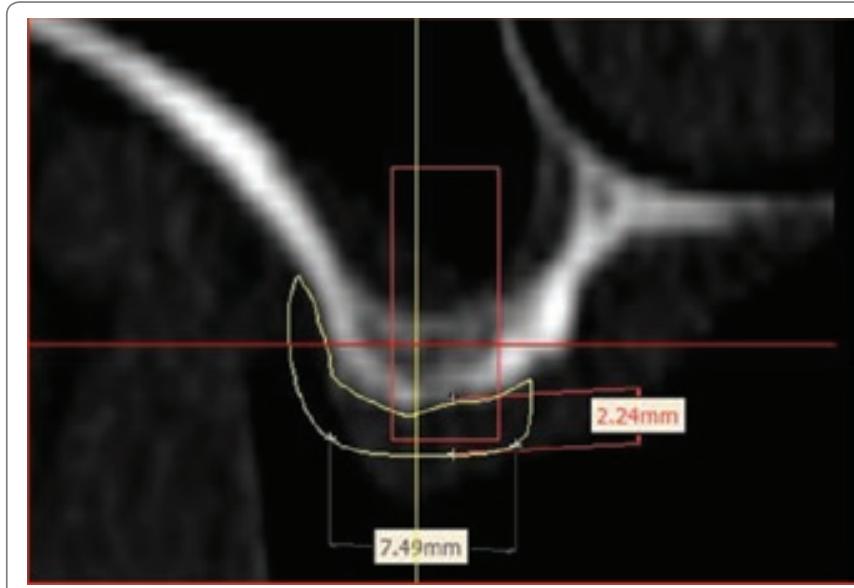

Figure 7: Virtual graft planning for tooth regions 26.

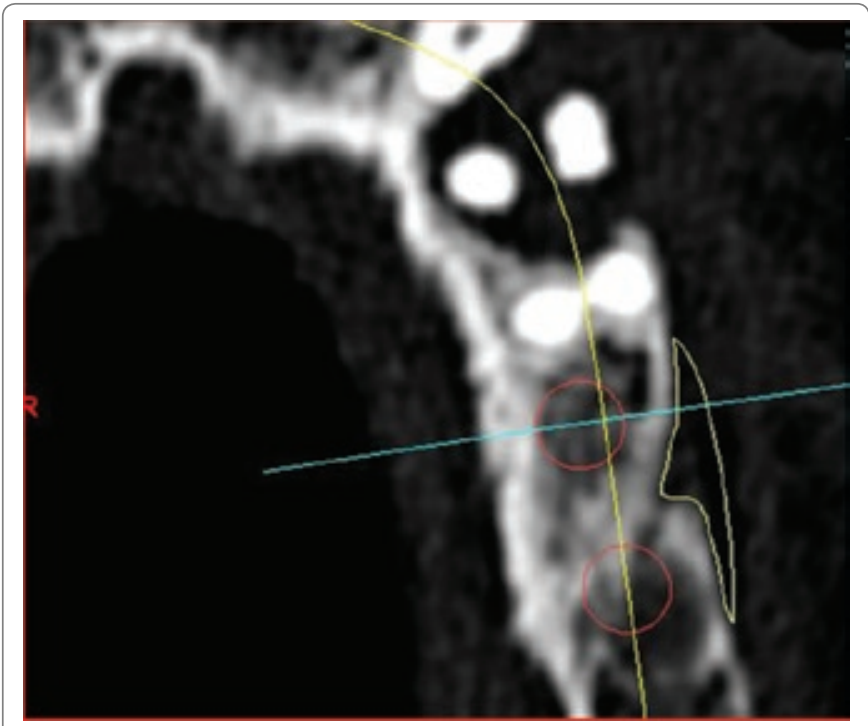

Figure 8: Virtual graft planning for tooth regions 26 and 27.

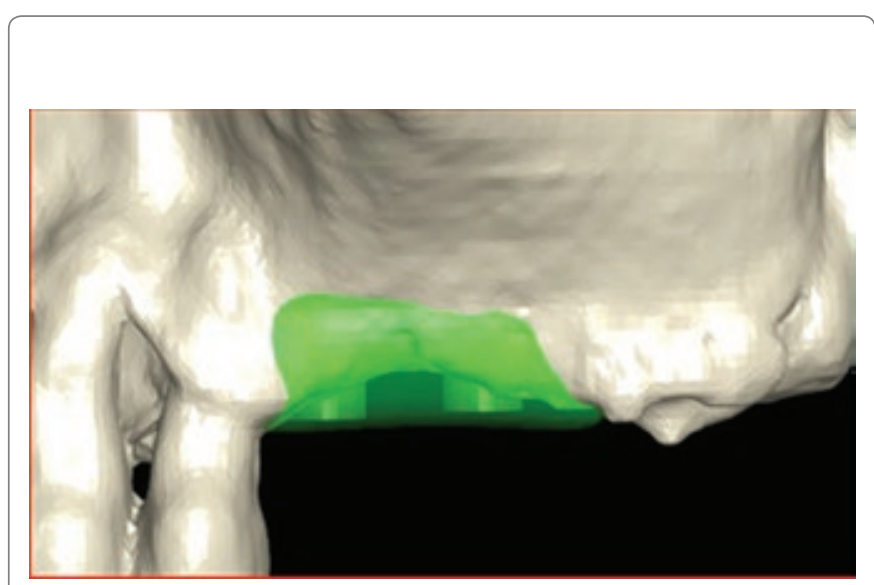

Figure 9: Virtual planning after grafting of the bone block onto the defect area.

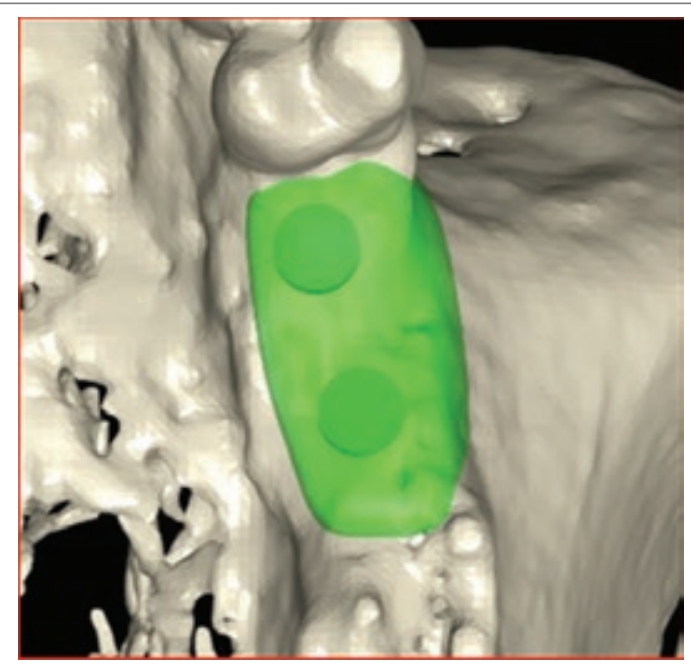

Figure 10: Virtual planning after grafting of the bone block onto the defect area.

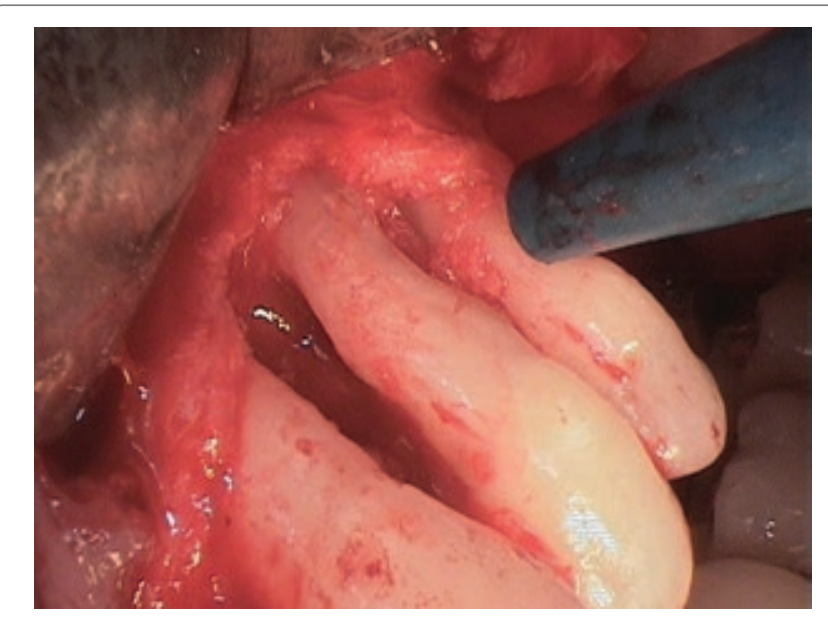

Figure 11: Smoothing of the root surface 24 and 25, complete removal of the granulation tissue with the aid of the piezosurgery technique.

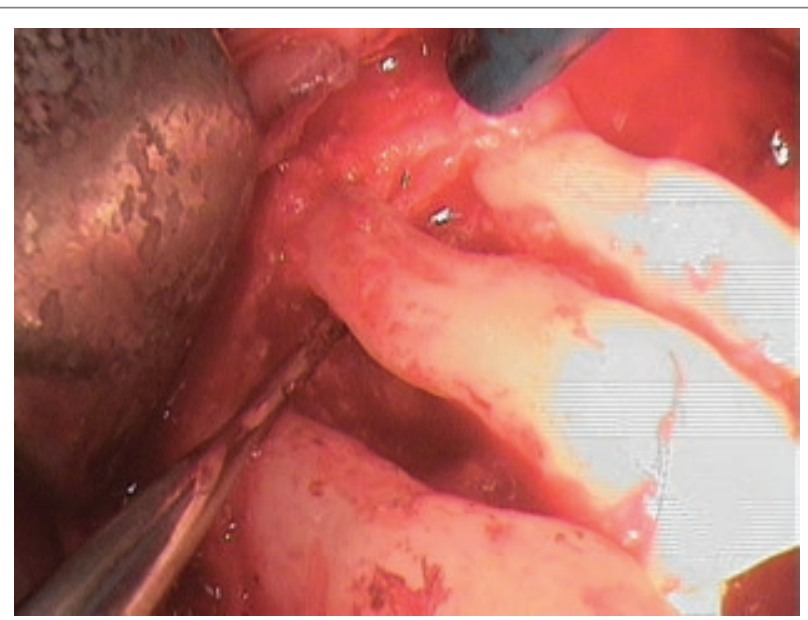

Figure 12: Smoothing of the root surface 24 and 25, complete removal of the granulation tissue with the aid of the piezosurgery technique. 
of the patient's extremely high compliance, the defect was filled in with a xenogeneic bone (Bio Oss collagen, Fa. Geistlich) replacement material after extensive open curettage (smoothing of the root surface, complete removal of the granulation tissue with the aid of the piezosurgery technique; (Figures 11 and 12) and the application of PrefGel ${ }^{\text {Txt }}$ and Emdogain ${ }^{\circ}$ (Straumann $\mathrm{GmbH}$ ). The filled defect was then covered with an absorbable membrane.

While this was taking place, the allogeneic bone-block graft was prepared using sodium chloride (Figure 13).

The bone block was fixed in place by use of osteosynthesis screws (Ustomed) and small uneven patches were levelled out using a particulate allogeneic substitute material (Puros Allograft Spongiosa Partikel [cancellous bone particles], Zimmer Dental GmbH, Munich) (Figure 1).

The augmentation material and augmented regions around teeth 24 and 25 were covered with an absorbable collagen membrane (CopiOs Pericardium Membrane, Zimmer Dental GmbH, Munich) and fixed in place with Titan Pins (Ustomed) (Figures 14 and 15).

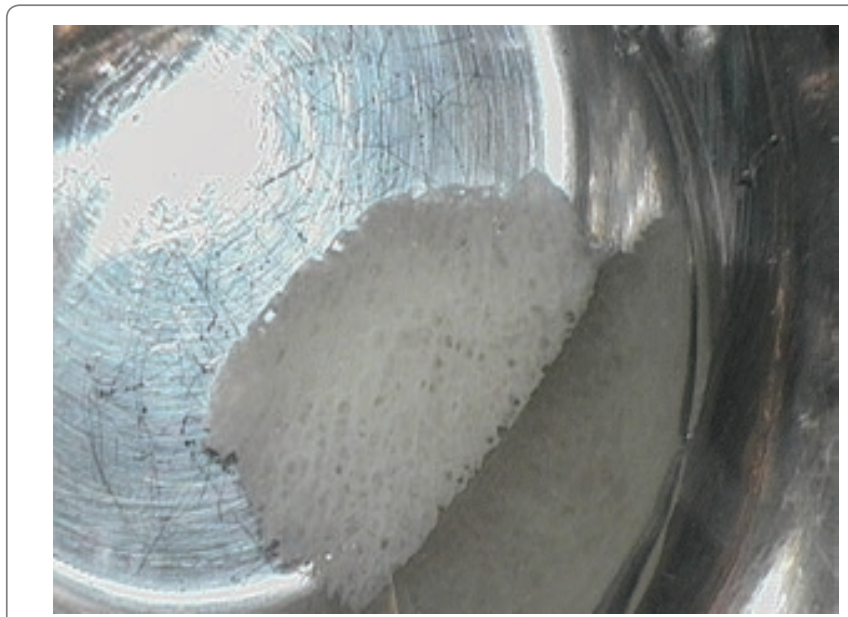

Figure 13: Preparation of the allogeneic bone-block graft using sodium chloride.

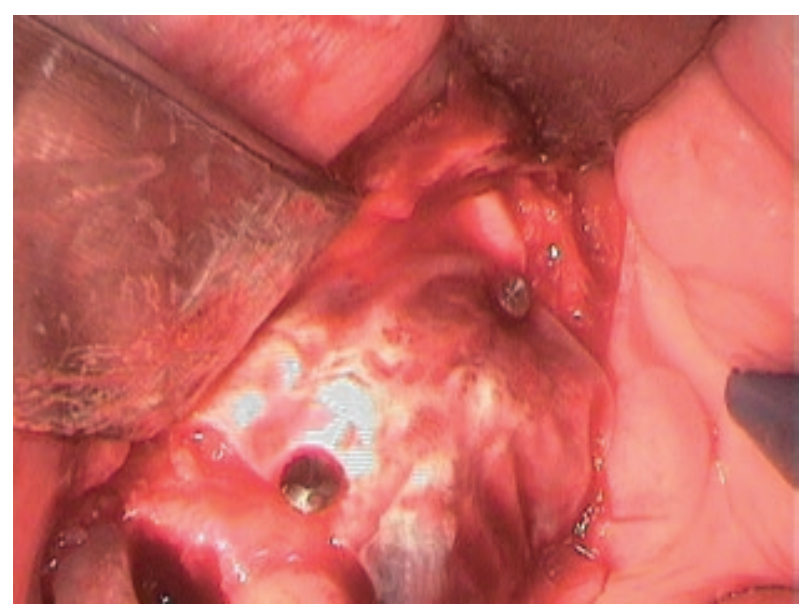

Figure 14: Covering of bone block and vertical defect with an absorbable membrane.
This was followed by tension-free suture closure using absorbable sutures (Glycolon 6/0, Resorba. Figure 16 shows the situation one day after surgery, Figure 17 eight days after surgery.

The patient received intra-operative antibiotic prophylaxis of $1000 \mathrm{mg}$ amoxicillin i.v. He also received postoperative antibiotic prophylaxis of $1000 \mathrm{mg}$ amoxicillin (1-1-1) and $500 \mathrm{mg}$ metronidazole for ten days (1-1-1). He was instructed to rinse his mouth with a $0.2 \%$ chlorhexidine solution and to use chlorhexidine gel in his dental-care routine.

Figure 18 shows the postoperative orthopantomogram.

After a six-month healing period of the augmentation material, surgical re-entry was performed. This showed that the graft had ossified normally (Figure 19).

The micro fixtures were removed and two implants (diameter: 4 $\mathrm{mm}$, length: $11.5 \mathrm{~mm}$; Zimmer Biomet) were inserted in tooth regions 26 and 27 during a simultaneous direct sinus lift. Autogenous bone chips were removed from the oblique ridge using a Safe Scraper. These chips were used to shape uneven areas in the region of insertion

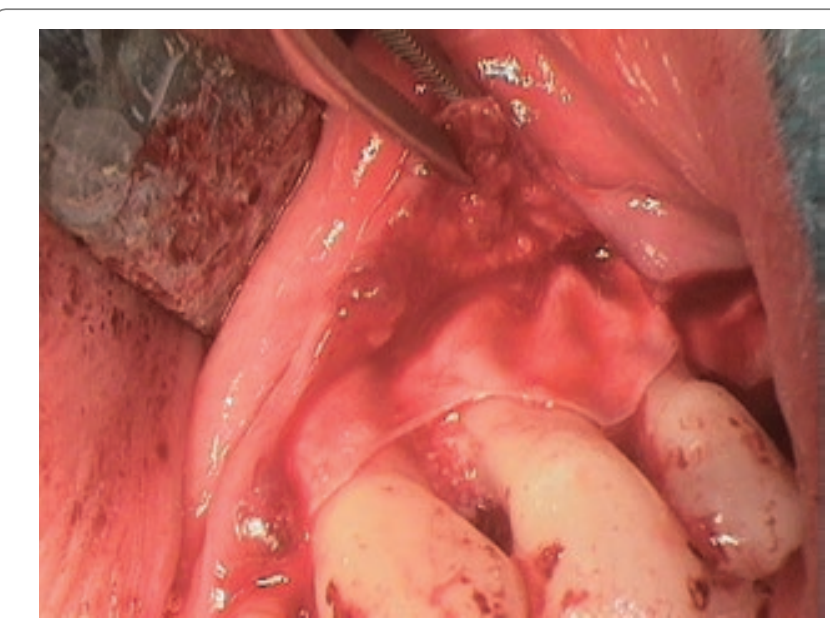

Figure 15: Covering of bone block and vertical defect with an absorbable membrane.

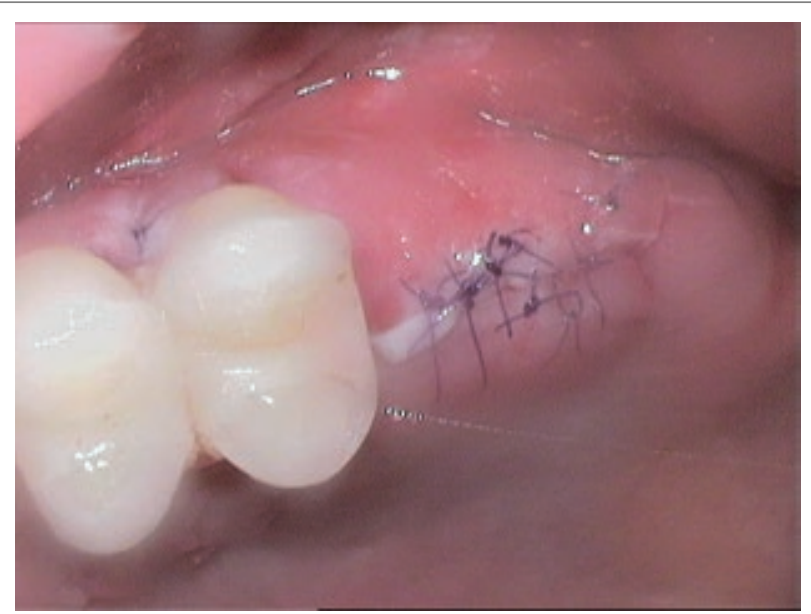

Figure 16: Site one day after surgery. 


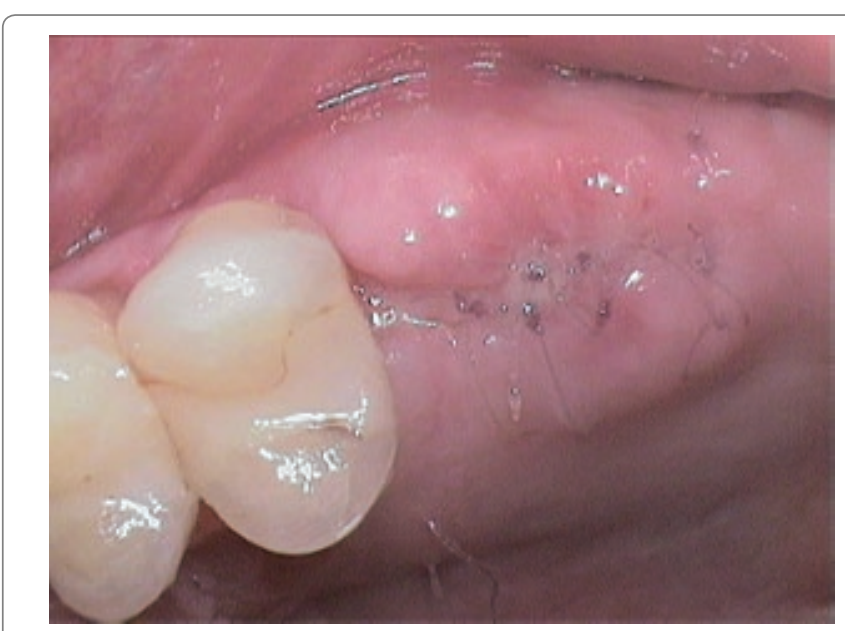

Figure 17: Site eight days after surgery.

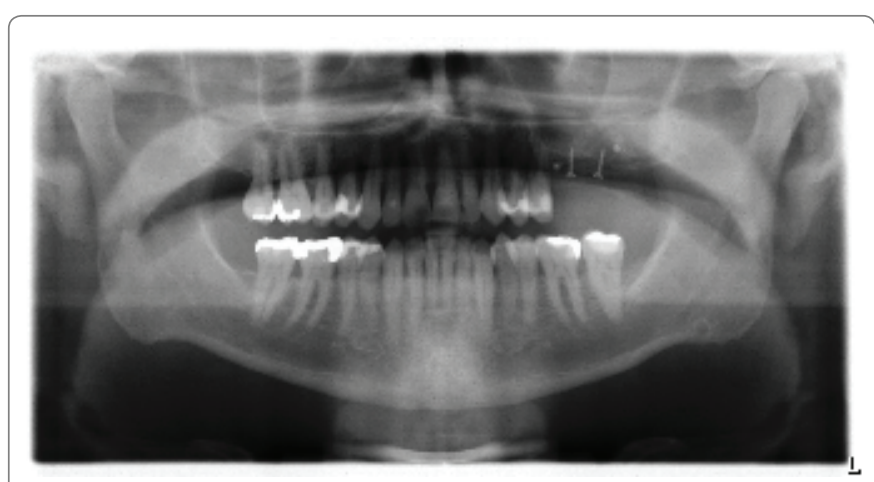

Figure 18: Postoperative OPG.

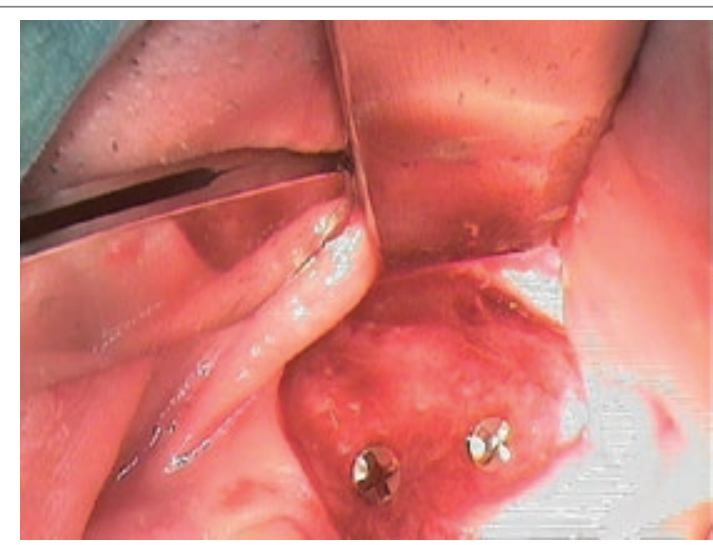

Figure 19: Situation at surgical re-entry after six months.

and to augment the sinus. The area was covered with an absorbable membrane applied using the bi-layer technique (Bio Gide, Fa Geistlich $\mathrm{GmbH}$ ) (Figures 20-25).

After a further six-month implant-healing period, the implants were then surgically uncovered by use of combined soft-tissue grafts and a scaffold (mucoderm, Straumann GmbH; Figure 26).

The prosthetic was fitted using CAD/CAM-milled abutments and transversally screw-retained, splinted, veneered metal-ceramic crowns (Figures 27-28, Dentaltechnik Hessel and Lutgen, Trier).

Figure 29 shows the radiological findings for tooth regions 24-27.
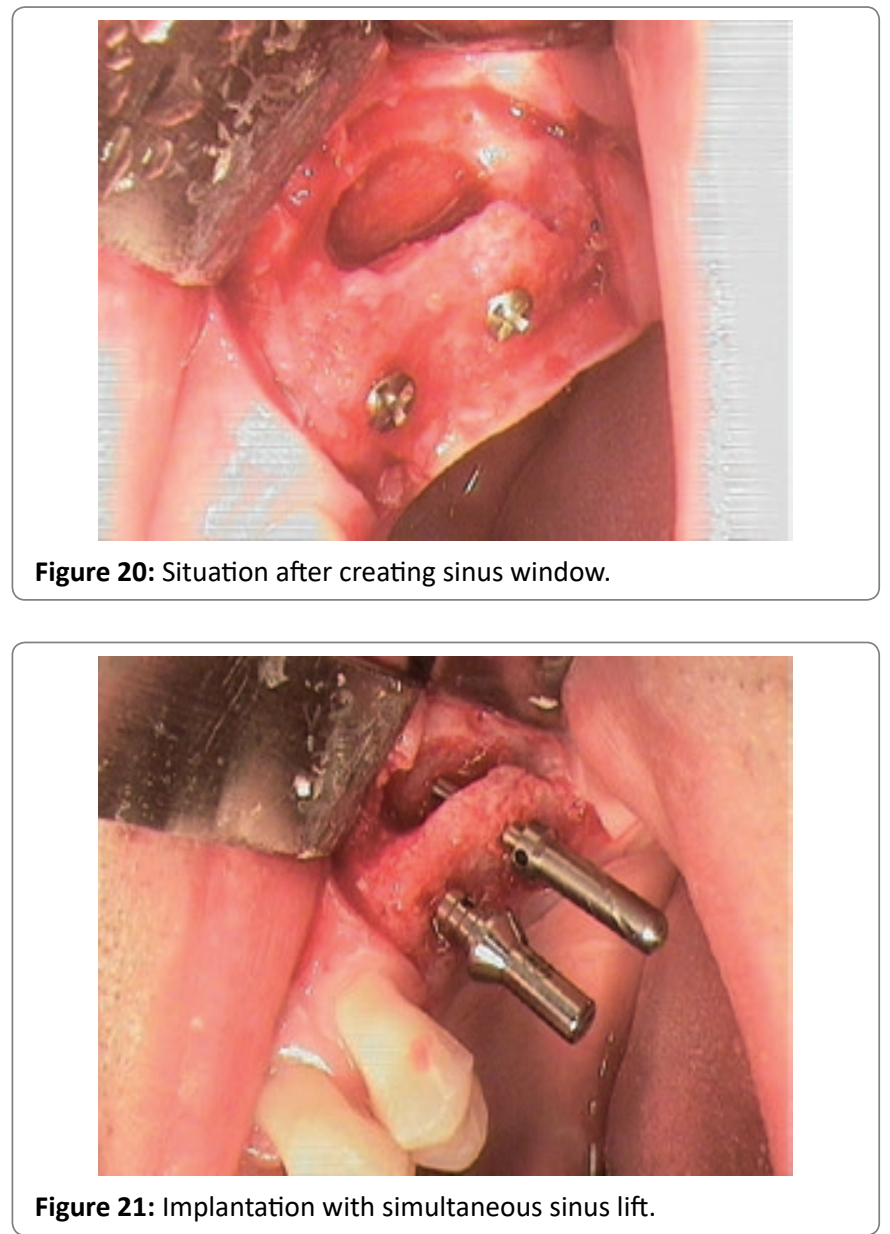

Figure 21: Implantation with simultaneous sinus lift.

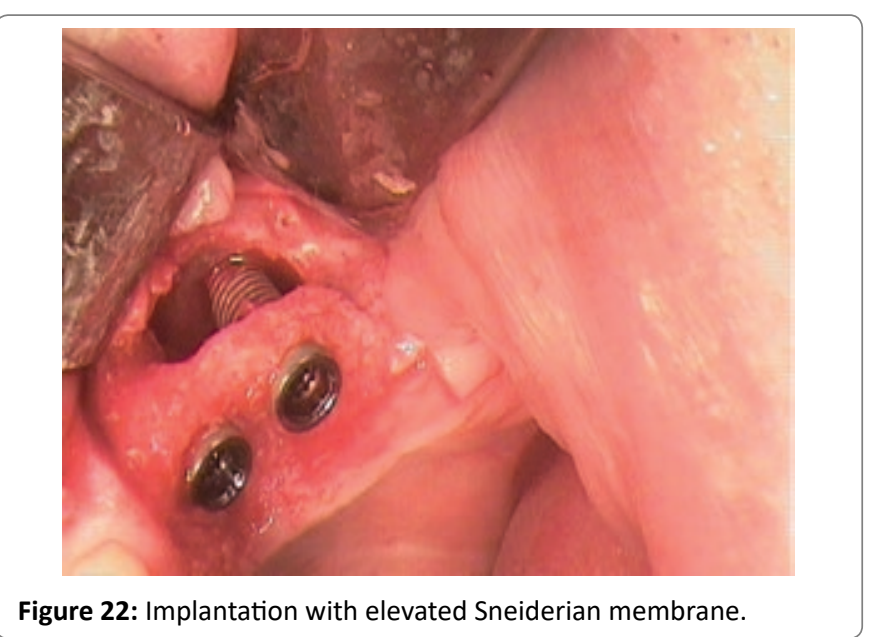

Note the periodontal regeneration of the area around tooth 25 , which can also be clinically observed in figures 30 and 31 .

\section{Discussion}

In the context of classic treatment concepts, teeth with bone resorption of $75 \%$ and above are classified as hopeless [4]. Such teeth are usually extracted. The previously mentioned 2011 study by Cortellini P [2], however, reports a 92\% five-year incidence of survival for "hopeless" teeth. This means that, even in extreme cases, a patient's desire to retain their teeth can be met by means of regenerative periodontal surgical measures. The patient case described here also 


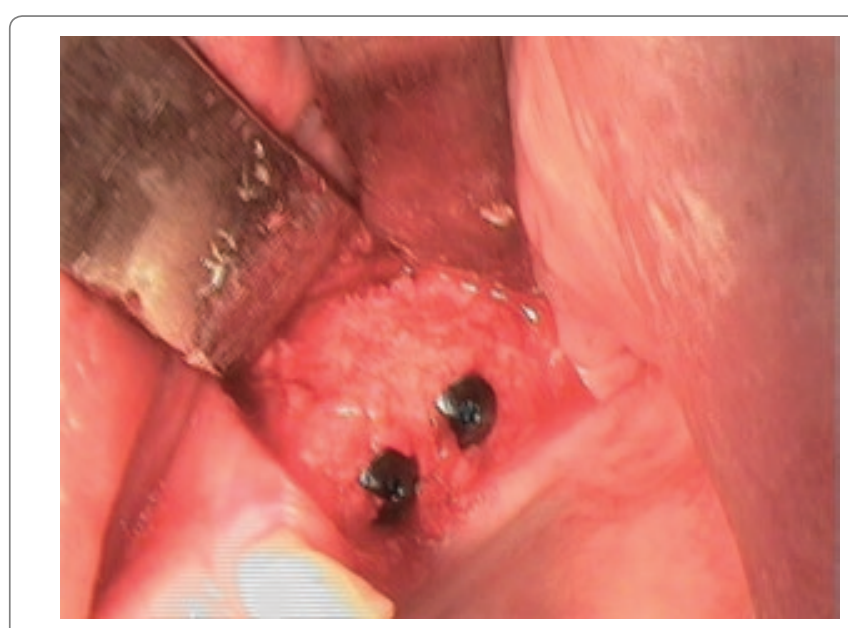

Figure 23: Implantation with further augmentation.

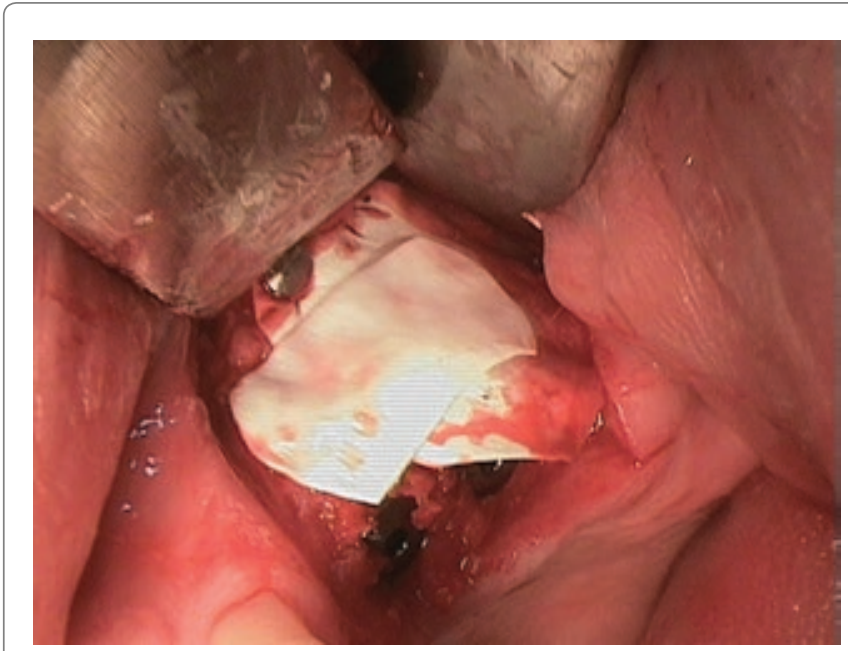

Figure 24: Covering the site with a membrane (bi-layer technique).

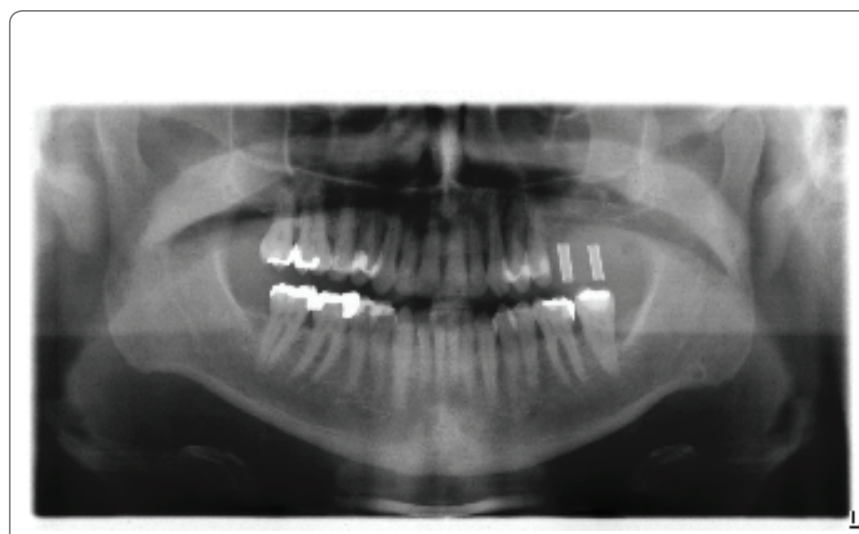

Figure 25: Postoperative OPG.

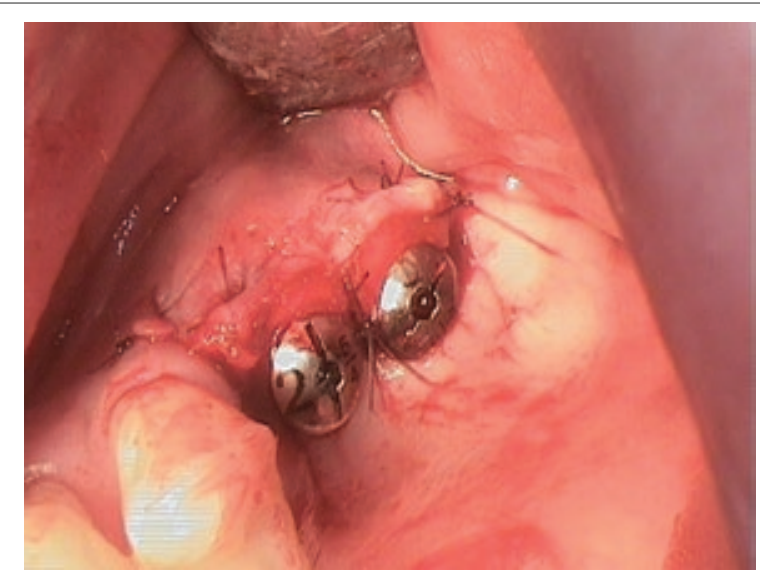

Figure 26: Condition after surgical exposure and insertion of mucoderm with healing caps in position.

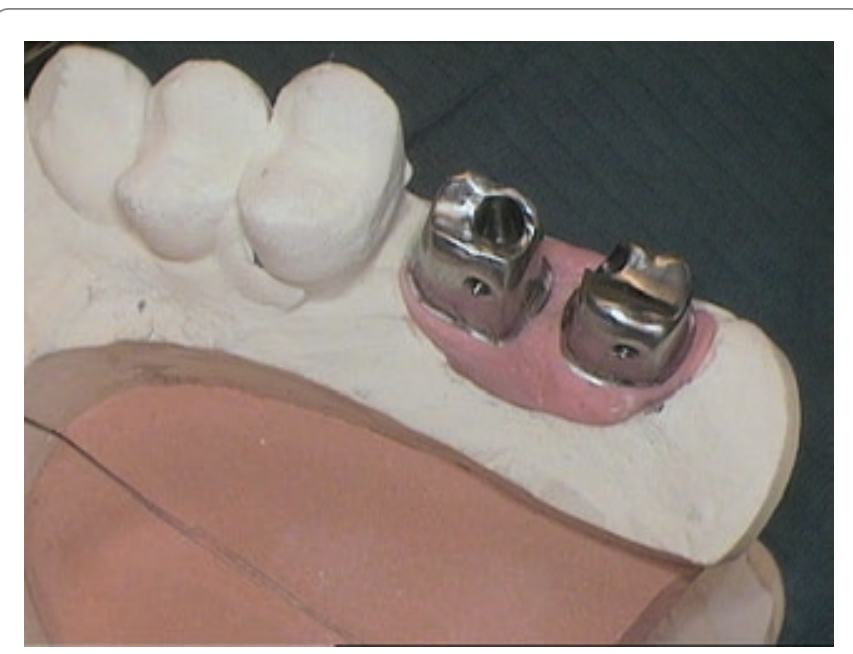

Figure 27: CAD/CAM-milled abutments for transversally screwretained crowns.

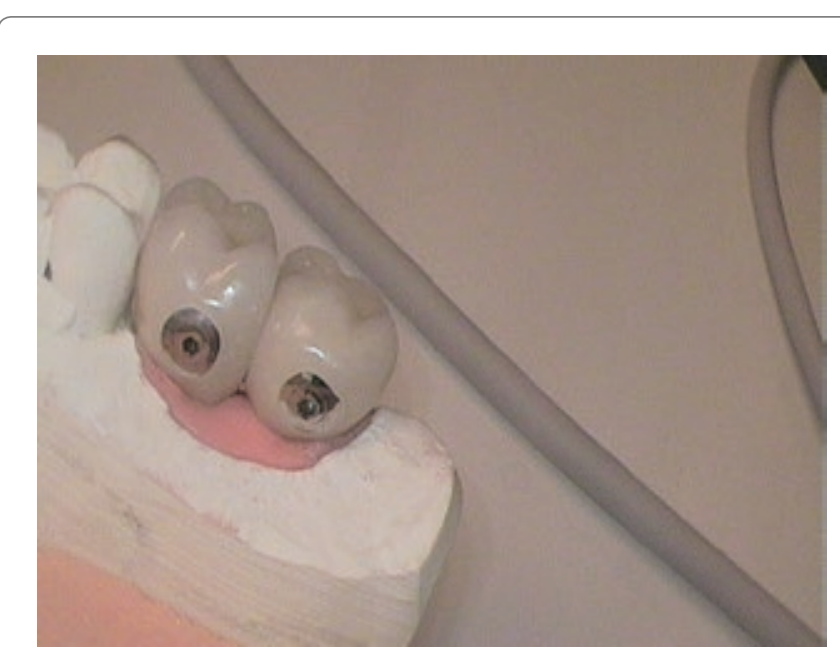

Figure 28: Transversally screw-retained crowns 26, 27 palatal sites. 


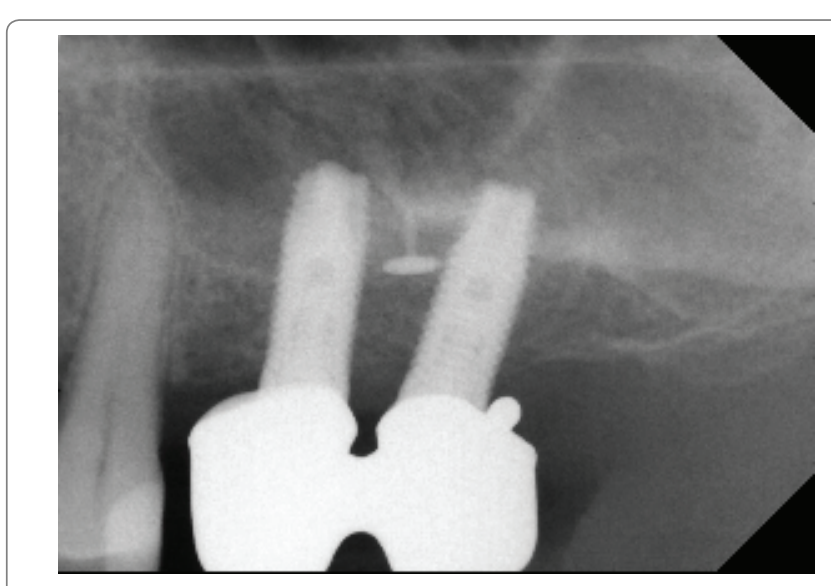

Figure 29: Try-in of the splinted superstructure on CAD/CAM abutments (image from $X$-ray follow-up).

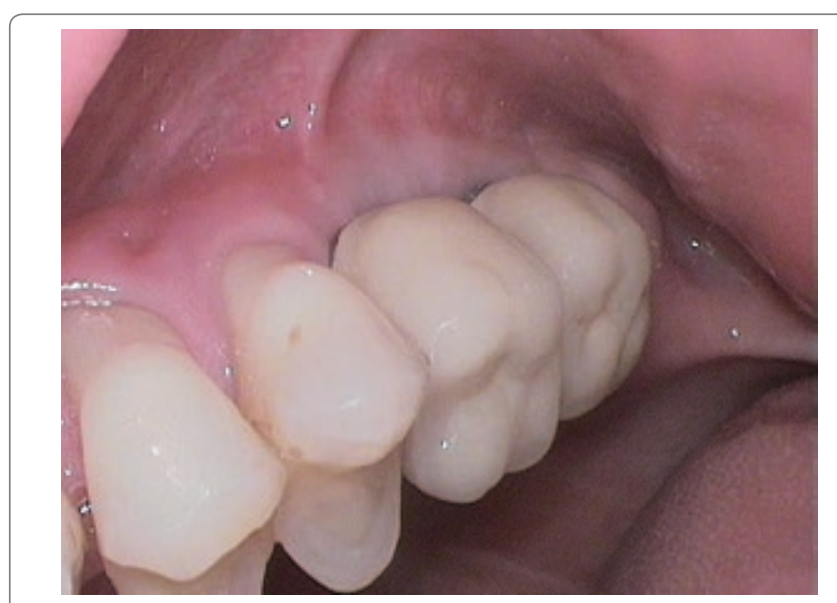

Figure 30: Vestibular view of the clinical situation with implant crown in position.

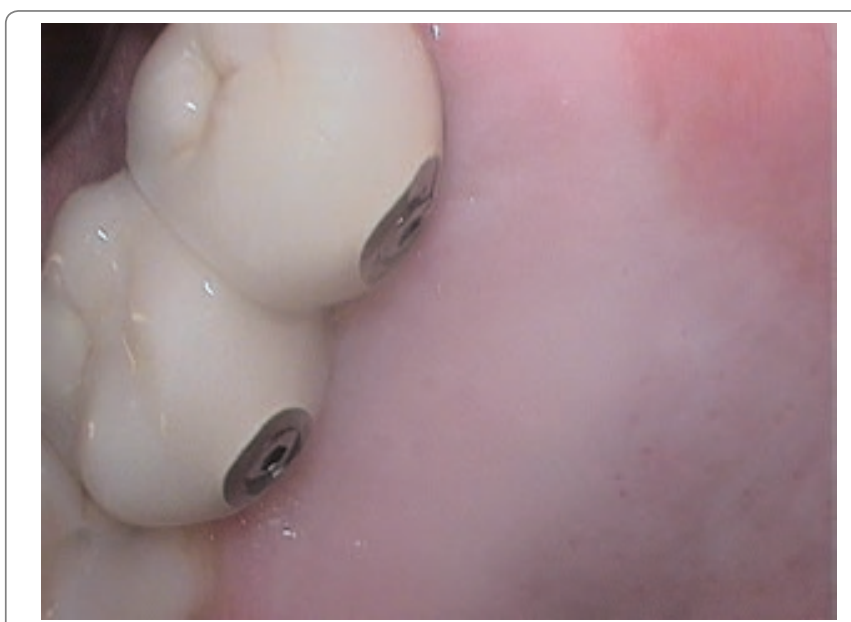

Figure 31: Palatal view of the implant crown with transversal screw. illustrates the possibility of performing a graft with subsequent implant treatment in a periodontally compromised dentition Christgau M [5].

\section{Conclusion}

The present patient case shows that even a periodontally compromised dentition is regenerative, augmentative and implantologically treatable. A comprehensive diagnosis, an evaluation of causal inter-connections and a specific, individualized treatment are indispensable. Especially with such multifactorial findings and therapies a close recall is mandatory and a high motivation and commitment of the patient an indispensable prerequisite.

\section{References}

1. Armitage GC (1999) Development of a classification system for periodontal diseases and conditions. Ann Periodontol 4: 1-6.

2. Cortellini P, Stalpers G, Mollo A, Tonetti MS (2011) Periodontal regeneration versus extraction and prosthetic replacement of teeth severely compromised by attachment loss to the apex: 5-year results of an ongoing randomized clinical trial. J Clin Periodontol 38: 915-924.

3. Würzler K (2015) Herstellung und Anwendung CAD/CAM-gefräster, patienten-spezifischer Knochenblöcke. Implantologie Journal 5: 3035.

4. Checchi L, Montevecchi M, Gatto MR, Trombelli L (2002) Retrospective study of tooth loss in 92 treated periodontal patients. J Clin Periodontol 29: 651-656.

5. Christgau M (2013) Implant at therapie im parodontal vorgeschädigen Gebiss. Parodontologie 24: 163-176. 